\title{
A numerical analysis of how permeability affects the development of pore water pressure in early age cemented paste backfill in a backfilled stope
}

\author{
RL Veenstra AMC Consultants Pty Ltd, Australia \\ MW Grabinsky University of Toronto, Canada \\ WF Bawden Mine Design Engineering, Canada \\ BD Thompson Mine Design Engineering, Canada
}

\begin{abstract}
This paper examines the behaviour of cemented paste backfill in the top part of the paste column. The paste within this section tends to exhibit isotropic behaviour and behaves more like a fluid than a solid. This trend will be examined using in situ instrumentation data obtained from test stopes.

This behaviour in this isotropic zone tends to be determined by consolidation properties as opposed to strength properties. In order to examine this behaviour three models were run. Two using a fixed permeability curve and the third using a function that determines the consolidation parameters as a function of curing age and applied stress. A comparison of these results will help determine how the paste is behaving at these early curing ages.
\end{abstract}

\section{Introduction}

Cemented paste backfill (CPB) has become a popular backfilling method for underground mining operations due to its delivery speed and versatility and its engineered strength. Originally there was limited interest in how the CPB behaves in an underground opening, particularly during its early curing ages. However, recent work has been conducted looking into this early age behaviour (Li \& Aubertin 2010; El Mkadmi et al. 2011; Helinski et al. 2011; Veenstra et al. 2013).

Numerical and analytical models have provided a starting point for these investigations in situ pressures within the stope and at the backfill barricade. The authors have developed a numerical model code, based in Itasca's FLAC3D (Itasca Consulting Group, Inc. 2012) that has been shown to replicate the CPB's stress behaviour during the filling of a stope. A companion paper at The 11th International Symposium on Mining with Backfill by Veenstra et al. (2014) presents more details on the development and verification of this model. This paper uses this model to examine the mechanisms of how the CPB is changing from a non-Newtonian fluid to a pseudo-solid. The paper will first examine in situ instrumentation results from several test stopes to define the area where this change is taking place and will discuss what is happening in that area.

The numerical model will then be used to examine the behaviour of the CPB within a simple 2D stope. Different permeability models will be used in order to try and mimic the sort of behaviour that was observed in the field.

In order to do this four permeability models will be used. The first model will use a typical permeability decay curve, the second will use a curve that has lower permeability during the first 24 hours of curing, the third will use the stress within the model and the curing age of the CPB to determine the permeability, and the fourth will not allow the upper areas of the CPB column to have effective stress. 


\section{Stope instrumentation}

Over the last seven years the University of Toronto ( $U$ of $T$ ) has been involved in a large CPB backfill research program involving the instrumentation of a series of test stopes at three different mine sites. In all of the stopes, total earth pressure cells (TEPC) and piezometers were installed at several locations within the stope, including the barricade, the brow, and at the centre of the main stope body. The inclusion of both the TEPCs and a piezometer meant that the effective stress of the CPB can be calculated at those locations. Figure 1 shows instrumentation results from three different stopes each from a different mine site (Thompson et al. 2011). Figures 1 (a) and (b) each show results from instrumentation points located in the middle of the body of the stope at about $2 \mathrm{~m}$ elevation, while Figure 1 (c) shows the results of two instrumentation points, both from the middle of the stope however the first at $2 \mathrm{~m}$ elevation and second at about $6 \mathrm{~m}$ elevation. Note that due to cable issues there was no vertical stress recorded for the second instrument cluster of Figure 1(c). For the rest of this paper the stope in Figure 1(a) will be referred to as Stope A, the stope in Figure 1 (b) as Stope B, etc.

The top graph for each instrumentation location shows the total stresses while the bottom graph shows the effective stresses. The instrumentation for each location follows a similar trend. There is a period of time, ranging from three to 18 hours depending on the stope, between when the CPB reaches the instrumentation and the onset of effective stress development. During this time there is isotropic stress behaviour in the CPB meaning that the CPB is displaying fluid-like behaviour instead of acting like a solid. Each stope had a different rise rate of CPB within the stope. This means that the Stope A had a $1.2 \mathrm{~m}$ high fluidic zone, Stope B a $4.5 \mathrm{~m}$ zone, and Stope $\mathrm{C}$ a $2.5 \mathrm{~m}$ zone. Determining what is happening in this section of the CPB column is important as it dictates what the CPB will do over the rest of the filling. The key to determining the behaviour within the fluidic zone is figuring out how the pore water pressure reduces.

\section{Pore water reduction in CPB filled stopes}

There are three main ways that water can be removed from the backfill mass. The first is the self-desiccation of the CPB due to cement hydration, the second is the relatively quick drainage of water from the backfill mass immediately next to the rock mass into the surrounding rock mass, and the last is due to the slower consolidation and drainage of the backfill mass.

The effects of self-desiccation in hydrating CPB have been demonstrated previously (Helinski et al. 2007; Simms \& Grabinsky 2009). However, it is important to note that the amount of water consumed in the CPB's hydration process is relatively limited due to the small amounts binder content that each mine uses. This limited water consumption, depending on the stiffness of the paste matrix, can generate varying pore water pressure changes.

It is possible that some relatively fast settling can occur in paste. There is evidence of water ponding on the surface of a fill surface, both in the field and in the laboratory. Field evidence supports CPB drainage as barricade fences regularly show water seepage during filling. While the amount of water being drained through the rock mass would be difficult to determine, it can be assumed that the amount would be relatively small, the area of drainage would stay close to the rock-CPB interface, and that the rock mass would be able to drain whatever amount of water was available.

The authors chose to perform a more detailed examination of the mechanisms behind the consolidation of CPB in order to determine the amount of consolidation that could be expected from a CPB backfill mass. 


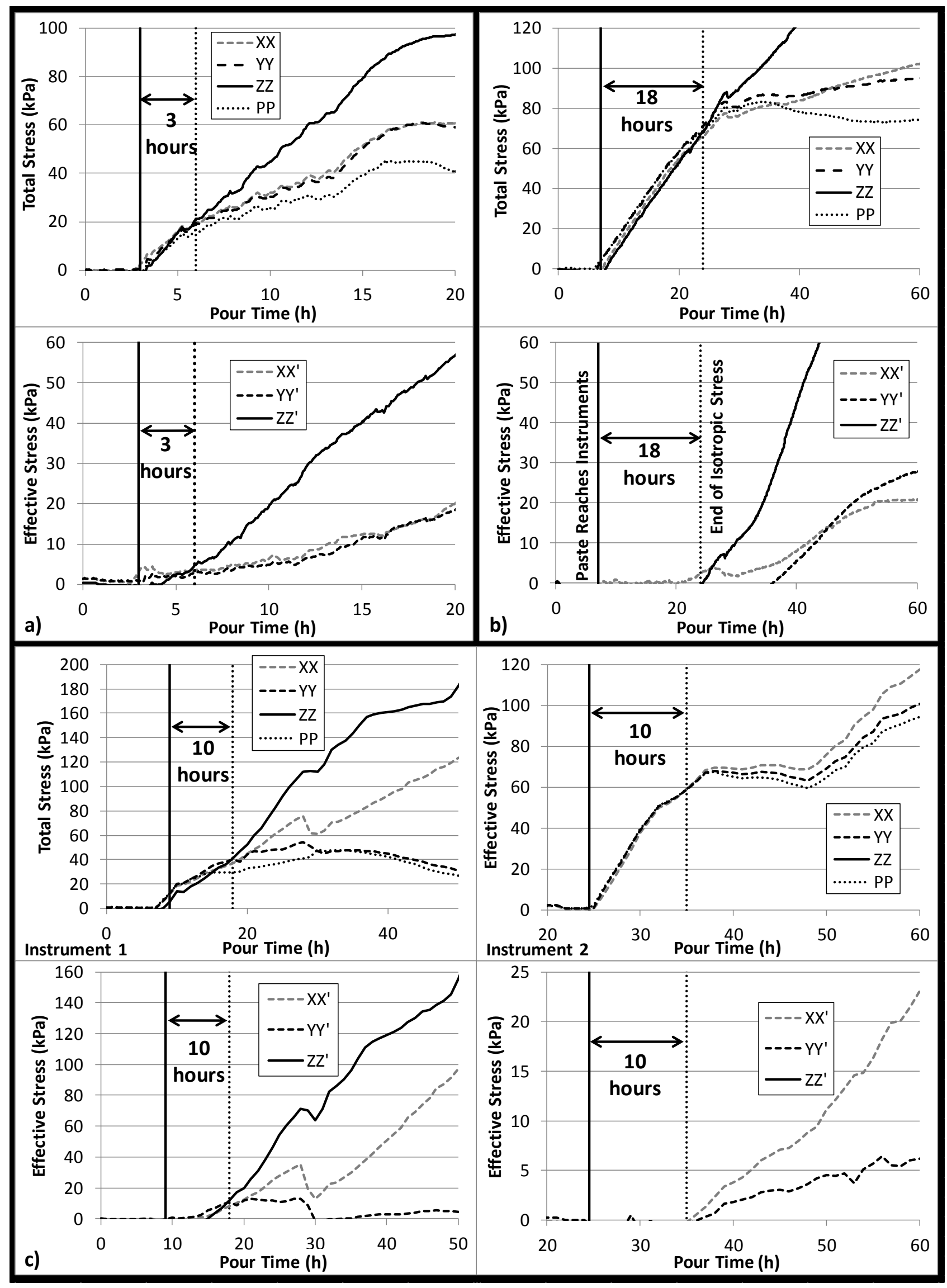

Figure 1 In situ instrumentation results from three test stopes; general locations of the instruments within the stopes are given in Section 2 


\section{Consolidation}

There are two main sets of material properties that dictate the behaviour of paste: its strength parameters and its consolidation parameters. For early curing age CPB, however, the most important set of parameters is consolidation as the early curing age CPB is weak.

Figure 2 shows compression curves (void ratio versus effective normal stress) for oedometer-style tests carried out on the same CPB recipes used to fill Stopes A, B, and C (Veenstra 2013). Each graph contains a family-of-curves showing the effect of curing age on the CPB. Common curing ages are 0-4, 12, 24, 48, 96 hours with some plots having a curing ages greater than 96 hours. The dots indicate the void ratio of the paste given the effective stresses observed in the instrumentation at each curing age.
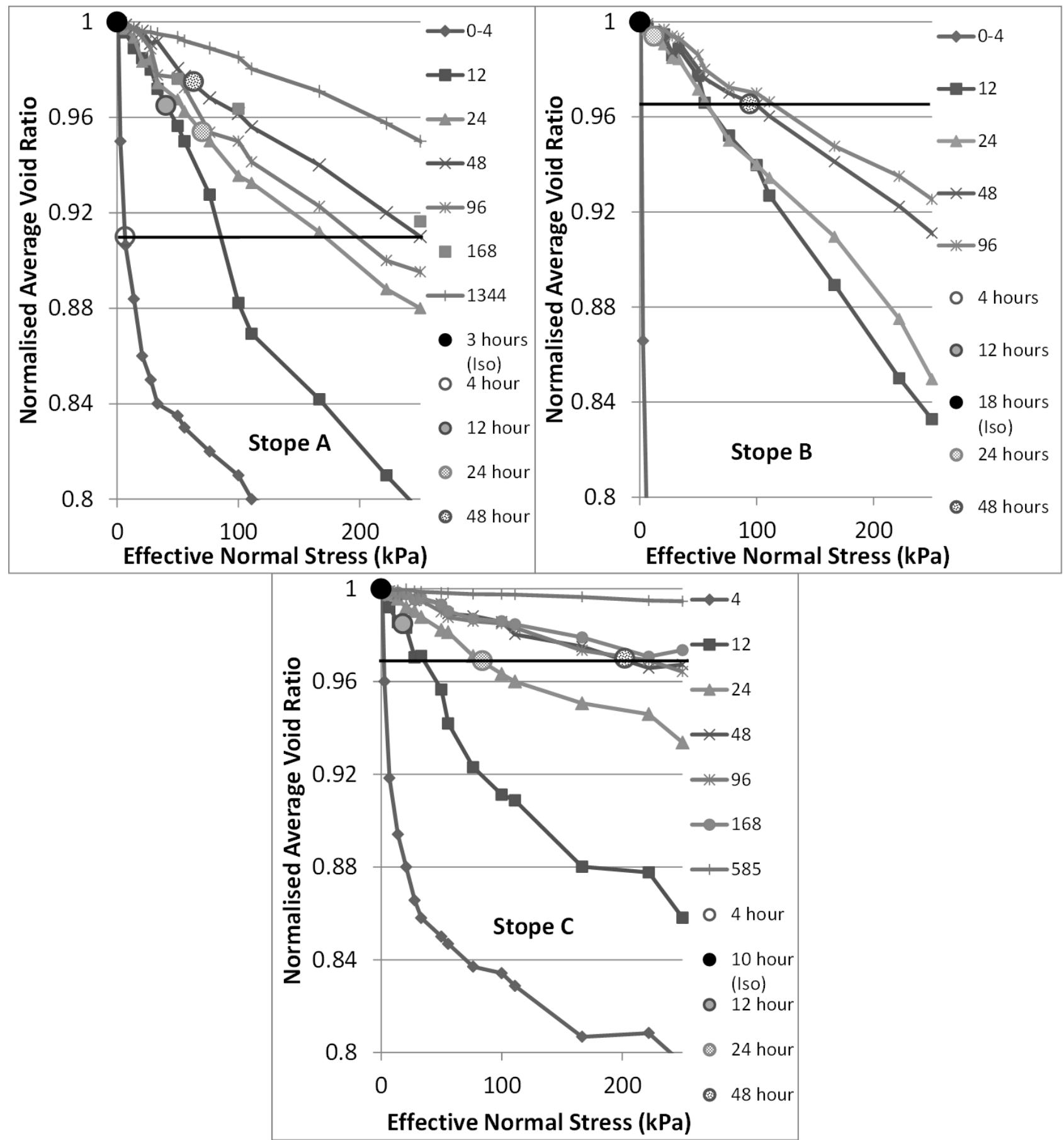

Figure 2 Compression curves for CPB recipes from three test stopes 
All three graphs show a similar trend, with CPB becoming stiffer with increased curing age. However, the rate of stiffness increase is different. Stopes $A$ and $C$ show more uniform increases while Stope $B$ has a very soft initial 12 hours. A comparison of the 96 hour cure curve shows that Stope $C$ has the stiffest CPB while the other two stopes have similarly stiff pastes.

Table 1 summarises the total and effective stresses seen in the instrumentation over the first 48 hours of curing. The effective stress results from Table 1 have been plotted on these graphs in Figure 2 . The largest potential time period for void ratio change (or consolidation) is during the first 24 hours of curing. However, the gain in effective stress in each stope was relatively small during that period, meaning that each of the $\mathrm{U}$ of $\mathrm{T}$ instrumented stopes would experience very low amounts of compression.

Table 1 Summary of total and effective stresses over time for three test stopes

\begin{tabular}{ccccccc}
\hline & $\begin{array}{c}\text { Length of iso. } \\
\text { stress period }\end{array}$ & $\begin{array}{c}\text { Four } \\
\text { hours }\end{array}$ & $\begin{array}{c}\mathbf{1 2} \\
\text { hours }\end{array}$ & $\begin{array}{c}\mathbf{2 4} \\
\text { hours }\end{array}$ & $\begin{array}{c}\mathbf{4 8} \\
\text { hours }\end{array}$ & $\begin{array}{c}\text { End of iso. } \\
\text { stress }\end{array}$ \\
& hours & $\mathbf{k P a}$ & $\mathbf{k P a}$ & $\mathbf{k P a}$ & $\mathbf{k P a}$ & $\mathbf{k P a}$ \\
\hline Stope A & 3 & 27 & 79 & 105 & 110 & 21 \\
Stope B & 18 & 21 & 53 & 93 & 167 & 70 \\
Stope C & 10 & 15 & 50 & 132 & 223 & 40 \\
& & & Effective vertical stress at curing age \\
Paste & stress period & Four & $\mathbf{1 2}$ & $\mathbf{2 4}$ & $\mathbf{4 8}$ & $\mathbf{E n d}$ of iso. \\
& hours & hours & hours & hours & stress \\
& hours & $\mathbf{k P a}$ & $\mathbf{k P a}$ & $\mathbf{k P a}$ & $\mathbf{k P a}$ & $\mathbf{k P a}$ \\
\hline Stope A & 3 & 6.7 & 40.24 & 70 & 62.5 & 0 \\
Stope B & 18 & 0 & 0 & 12 & 94 & 0 \\
Stope C & 10 & 0 & 18 & 84 & 202 & 0 \\
\hline
\end{tabular}

Black lines have been drawn on the graphs in Figure 2 to indicate the greatest change in void ratio given all of the effective stresses. This shows that minimal amount of consolidation has taken place in the $U$ of $T$ stopes. There is an observed relationship between the length of the isotropic stress period and the amount of consolidation experienced, meaning that if a CPB only remains isotropic for a short time it will have a greater amount of compression as seen in Stope A. However, what is generally observed in all of the stopes is that the by the time the CPB material skeleton starts to take load it is generally strong and stiff enough to resist the weight of the material above it.

The minimal change in void ratio, shown in Figure 2, is comparable to the difference observed between the void ratios of freshly prepared laboratory samples and the void ratios determined from in situ samples from the test stopes, given the same recipe. Furthermore, these in situ samples all had similar void ratios and did not show much relationship with change of depth (Grabinsky et al. 2014). This indicates that there is a slight change in consolidation experienced between fresh paste and deposited paste, but that this change is not dependent on the amount of material above. This may indicate that the same process, which likely occurs early in the curing cycle before the CPB has gained stiffness and strength, is responsible for whatever small amount of consolidation has happened. 


\section{$5 \quad$ Numerical modelling of CPB - permeability}

There is empirical proof that the some of the water in the CPB does drain towards the rock mass as seen by the seepage through the barricade. This suggests that a slight amount of drainage/consolidation does occur and could explain the difference in observed void ratios between laboratory prepared and in situ samples.

In order to examine the reduction of pore water pressure, three models will be run using different combinations of the consolidation parameters: stiffness and permeability. All of the models will use material parameters from one type of CPB. However, first it is important to discuss the origin of these material parameters.

\subsection{Determination of consolidation material properties}

The numerical model requires input of the bulk $(K)$ and shear $(G)$ moduli, and the permeability $(k)$ be inputted. These parameters were determined from the same consolidation testing that generated the compression curves seen in Figure 2. The two parameters determined were the coefficient of volume compressibility $\left(m_{v}\right)$ and the coefficient of consolidation $\left(C_{v}\right)$. Both of these parameters were determined from the incremental loading regime. These parameters can be plotted versus cure time or versus normal stress. However, these parameters are actually functions of both cure time and stress.

A high $m_{v}$ value indicates a soft material. Its inverse is called the confined modulus $\left(M_{v}\right)$. The confined modulus and Poisson's ratio $(\mathrm{v})$ can be used to determine the bulk and shear moduli. It should be noted that the Poisson's ratio could not be measured from the laboratory tests performed and its change due to increased curing time has been estimated. Figure 3 shows an example of the $v$ and $m v$ curves determined from the laboratory testing.

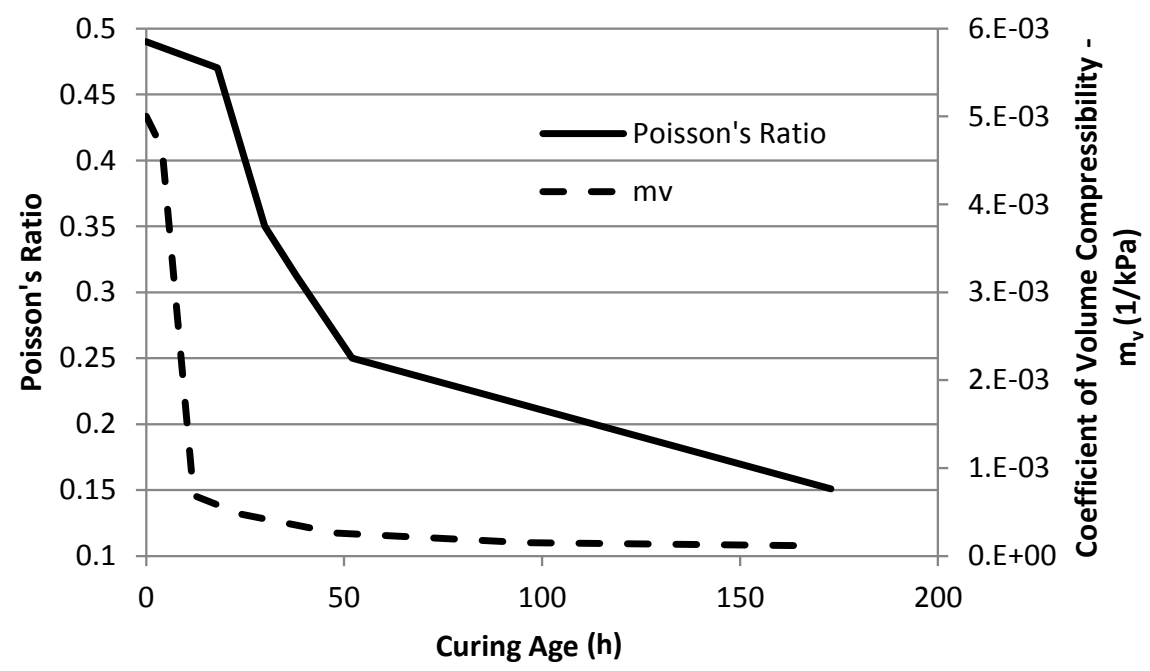

\section{Figure 3 Example of Poisson's ratio and coefficient of volume compressibility $\left(m_{v}\right)$ curves with curing age}

The coefficient of consolidation is the rate at which a material undergoes consolidation in response to increased load. The hydraulic conductivity or permeability of a material can be calculated using the following equation:

$$
k=C_{v} m_{v} \gamma_{w}
$$

Where:

$k=$ is the hydraulic conductivity or permeability.

$\gamma_{w}=$ is the unit weight of water.

$m_{v}=$ is the coefficient of volume compressibility. 
$C_{v}=$ is the coefficient of consolidation.

This equation was used because it is a common method for determining permeability and is easy to calculate as all of the necessary parameters are determined during the data analysis of the consolidation testing. However the use of this equation means that permeability and $m_{v}$ are related through $C_{v}$.

\subsection{Description of different models}

The following section describes the three models that will be compared. Note that the same Poisson's ratio and strength parameters will be used throughout. For more information on the determination of the strength parameters refer to Veenstra et al. (2012) or Veenstra (2013). All three models also assumed that the rock is infinitely more permeable than the paste and have a PWP $=0$ boundary condition at the rock-paste interface.

The first model was run using a standard permeability decay curve. The black line in Figure 4 shows this curve as determined from laboratory testing (Veenstra 2013).

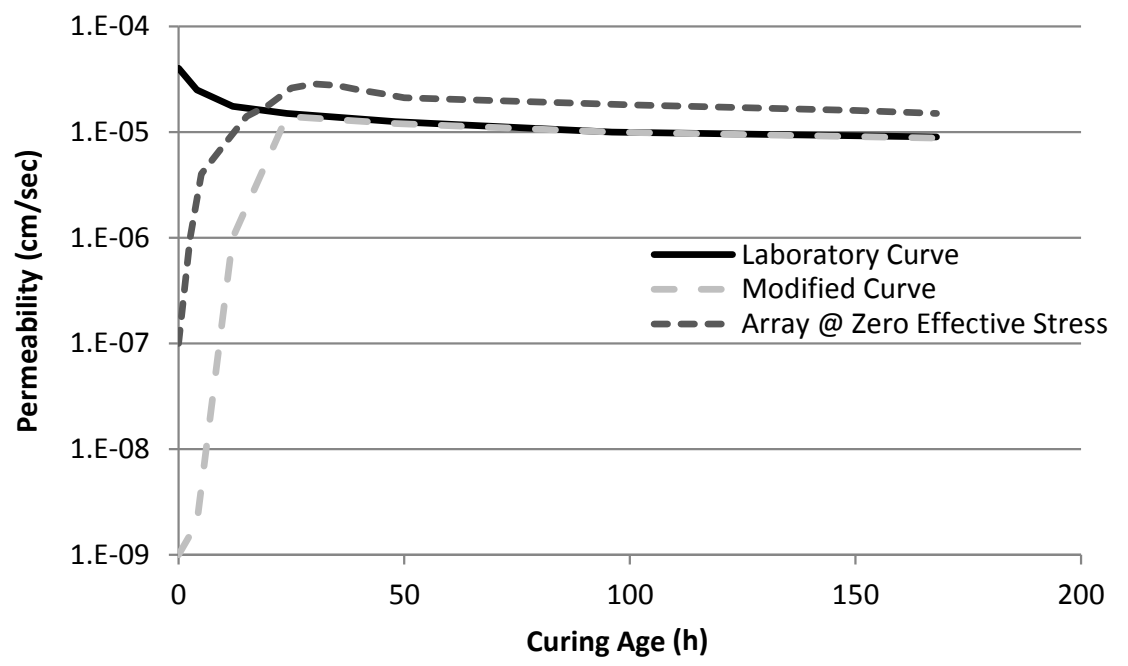

\section{Figure 4 Modelled permeability curves}

The second model was run using a modified decay curve. While calibrating the numerical code against instrumentation values it was found that lowering the permeability during the early curing ages 'brute-forced' the model into producing results that more closely followed the instrumentation. The dashed, light grey curve in Figure 4 shows such a modified decay curve used, which was used in the second model. See Veenstra (2013) for more information on these model results.

The third model determines the consolidation properties $\left(C_{v}\right.$ and $\left.m_{v}\right)$ as a function of stress and curing age and inputs them in the appropriate zone. The model then calculates the necessary parameters using the methodology presented in Section 5.1. The zones are then updated as the model fills the stope. However, for comparative purposes the permeability at an effective stress equal to zero was plotted on Figure 4 as a dashed, dark grey line.

The models will be referred to as BL for the baseline permeability curve, LP for the modified permeability curve, and AR for the model using the functions based on stress and time. The focus of the results will be in representing how the different models represent permeability and specific discharge. Specific discharge is analogous to the flow of water out of the zone and is shown as a magnitude. Note that the permeability will not change in either the BL or LP models, as this is an input, but will change in the AR model. The specific discharge will change in all three models. From previous modelling it was found that the BL model typically did not produce similar results to the instrumentation but the LP model did. Therefore, a large part of this comparison will be to see how the AR method compares to the two. 


\subsection{Modelling results}

The modelling results are presented in two different formats. The first format is to use contour plots, as these provide a 'big picture' understand of how the different models compare with each other. The second method is to present how a parameter changes at a particular zone over time. However, a brief description of the stope geometry is required.

The same model setup was used for all of the model runs. The model geometry was $12 \mathrm{~m}$ wide and $18 \mathrm{~m}$ high but was run in a half model configuration (effectively decreasing the amount of model zones in half). This configuration meant that the model was run in a $2 \mathrm{D}$ mode meaning that the model was one zone thick in length. The rise rate used was $0.2 \mathrm{~m} / \mathrm{h}$, meaning that the total fill time for the stope was 90 hours. Figure 5 shows a schematic of the stope model.

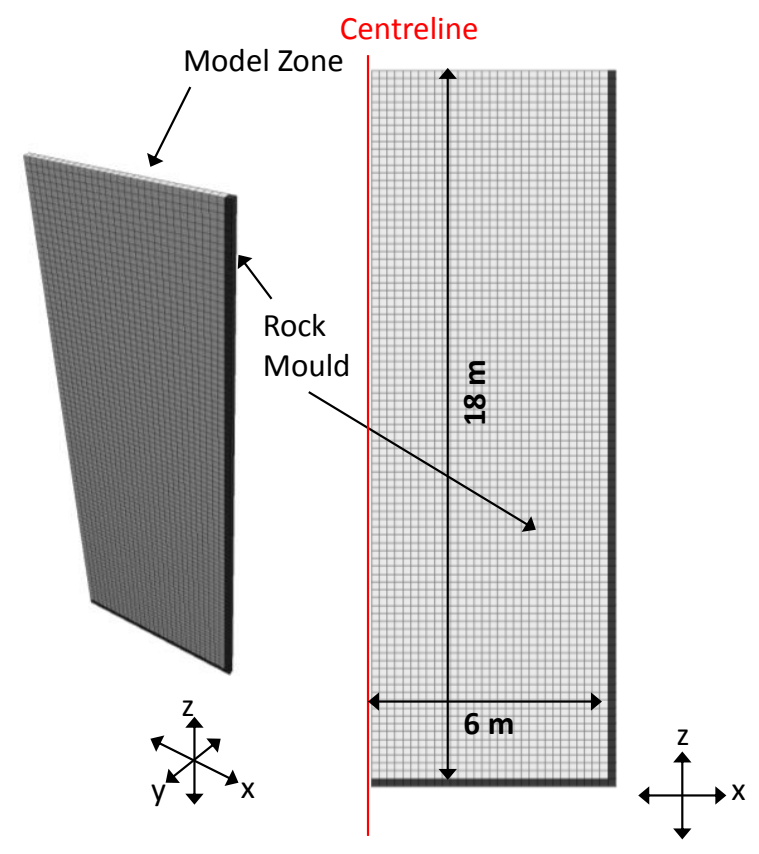

\section{Figure 5 Schematic of stope model}

Nine zones where monitored with time, with three of the zones being at $1 \mathrm{~m}$ elevation $(11,12,13)$, three at $4 \mathrm{~m}$ elevation $(14,15,16)$, and three at $12 \mathrm{~m}$ elevation $(17,18,19)$. At each of the three heights the monitored zones were at the centreline, halfway between the centreline and the rock wall, and directly adjacent to the rock wall.

\subsubsection{Isotropic stress period}

Figure 6 is a plot showing the vertical and horizontal effective stresses at 14 (centreline of stope at $4 \mathrm{~m}$ elevation). At this elevation the paste would have reached the monitoring point at 20 hours. This plot shows that the stresses in the BL model start to climb at 20 hours, indicating that this model does not have any period of isotropic behaviour as observed in Figure 1. However, both the AR and the LP models show a period of isotropic behaviour; the AR model for three hours and the LP model for 18 hours. This shows that the stress-time method is capable of generating an isotropic stress. 


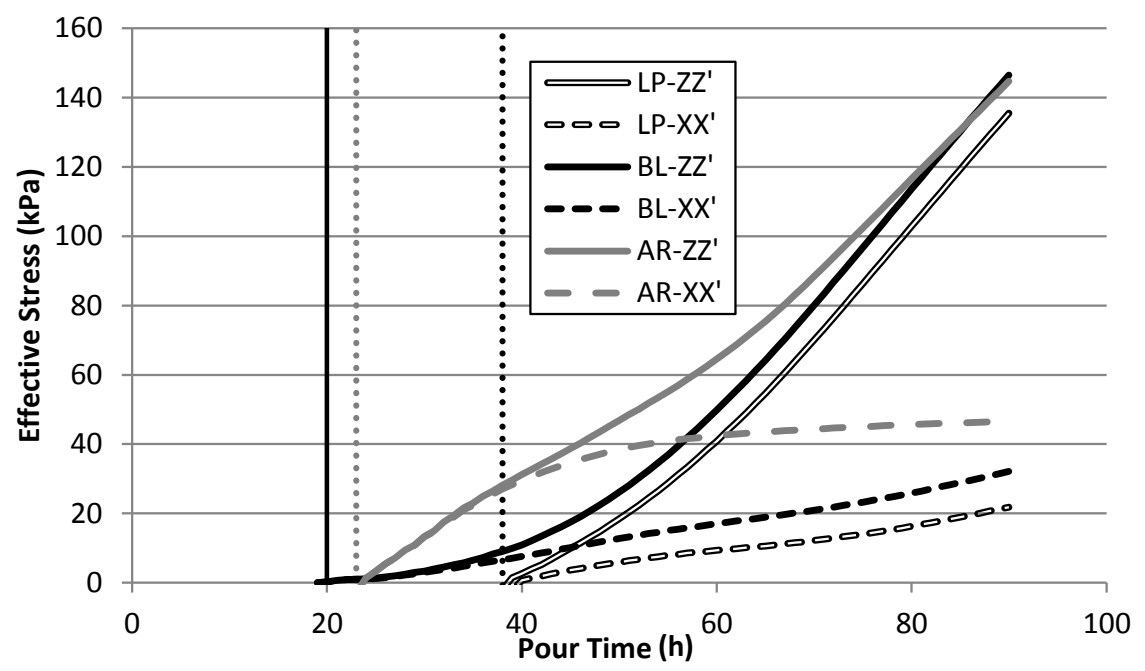

Figure 6 Vertical and horizontal effective stresses at monitoring point 14

There are some discrepancies between the effective stress curves. Both the BL and the LP models show similar behaviour with a gradual increase in both the vertical and horizontal stresses. The AR model curve behaves differently, with a much sharper increase in both stresses followed by a more gradual increase. This indicates that the pore water pressure, at least at this point, is behaving differently than the other models. This will be investigated further in the next section.

\subsubsection{Contour plots}

Figure 7 shows the contour plots for permeability, specific discharge, pore water pressure (PWP), and vertical effective stress (ZZ'). Four different curing ages are shown; 25 hour, 50 hour, 75 hour, and 90 hour (filling complete).

The contour plots for PWP and ZZ' are included to examine the similarity between the three models. All of the contour plots show similar trends though the PWP is lower in the AR model, particularly when filling the bottom of the stope. This in turn does affect the effective stress contours. This discrepancy is probably due to how the stress-time method is affected by being close to the bottom of the stope.

All of the permeability contour plots show a similar trend, that as the top of the CPB moves up the stope height it is followed by similar contour pattern. This was expected in the BL and LP models as these parameters are model inputs; hence this is why these contours show no variation through the $x$-direction. However, it is interesting to see the AR model shows a similar trend even though its permeability is being calculated independently. The similarity of the AR contour pattern indicates that the top of the CPB column must experience similar stresses throughout the filling process. Note also that the location of the high permeability zone in the AR model corresponds to the high permeability band seen in the LP model.

The specific discharge contours for all three models are different but show similar trends. In the 25 hour contour plots the majority of the discharge, for all three models, is taking place through the floor. However, as the CPB column grows the amount of discharge through the floor reduces and the majority of discharge starts to take place through the walls. The area of highest discharge migrates up the walls with increasing CPB height. However, the LP and AR contours appear more similar to each other than either do towards the BL model. 


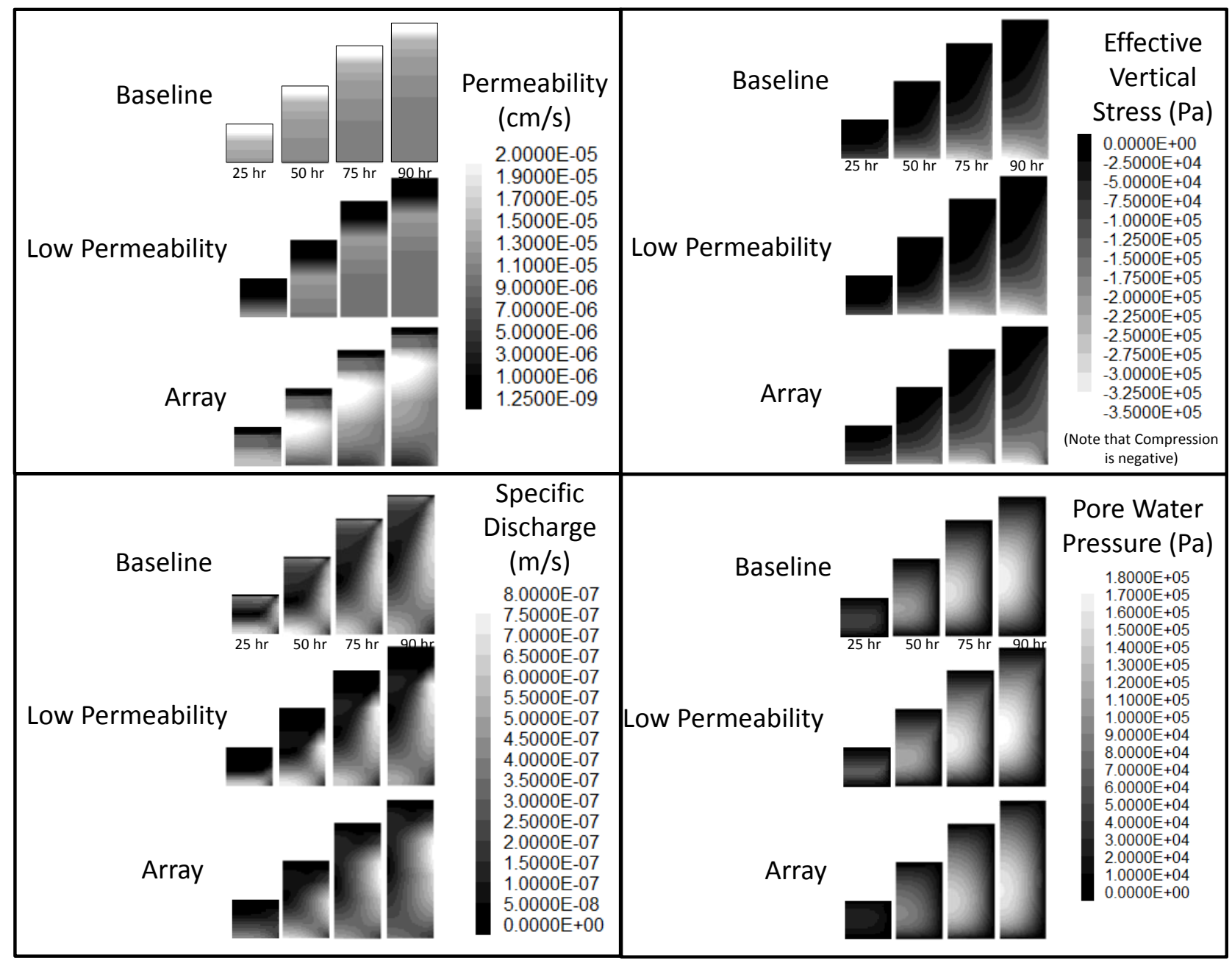

Figure 7 Contour plots of permeability and specific discharge for all three models at 25, 50,75 , and 90 hours of filling

\subsubsection{Permeability and specific discharge with pouring time}

Figure 8 contains six graphs showing how permeability and specific discharge change with pouring time. The permeability graphs are on the left and the specific discharge graphs are on the right. The lower graphs contain the results for the bottom three points $(11,12,13)$, the middle graphs for the middle points $(14,15$, $16)$, and the upper graphs the upper points $(17,18,19)$. Each graph shows a time lag, with the upper graphs showing more of a lag the lower graphs. This is due to the differences in heights as the CPB will reach these higher zones later than it would reach the lower zones. 

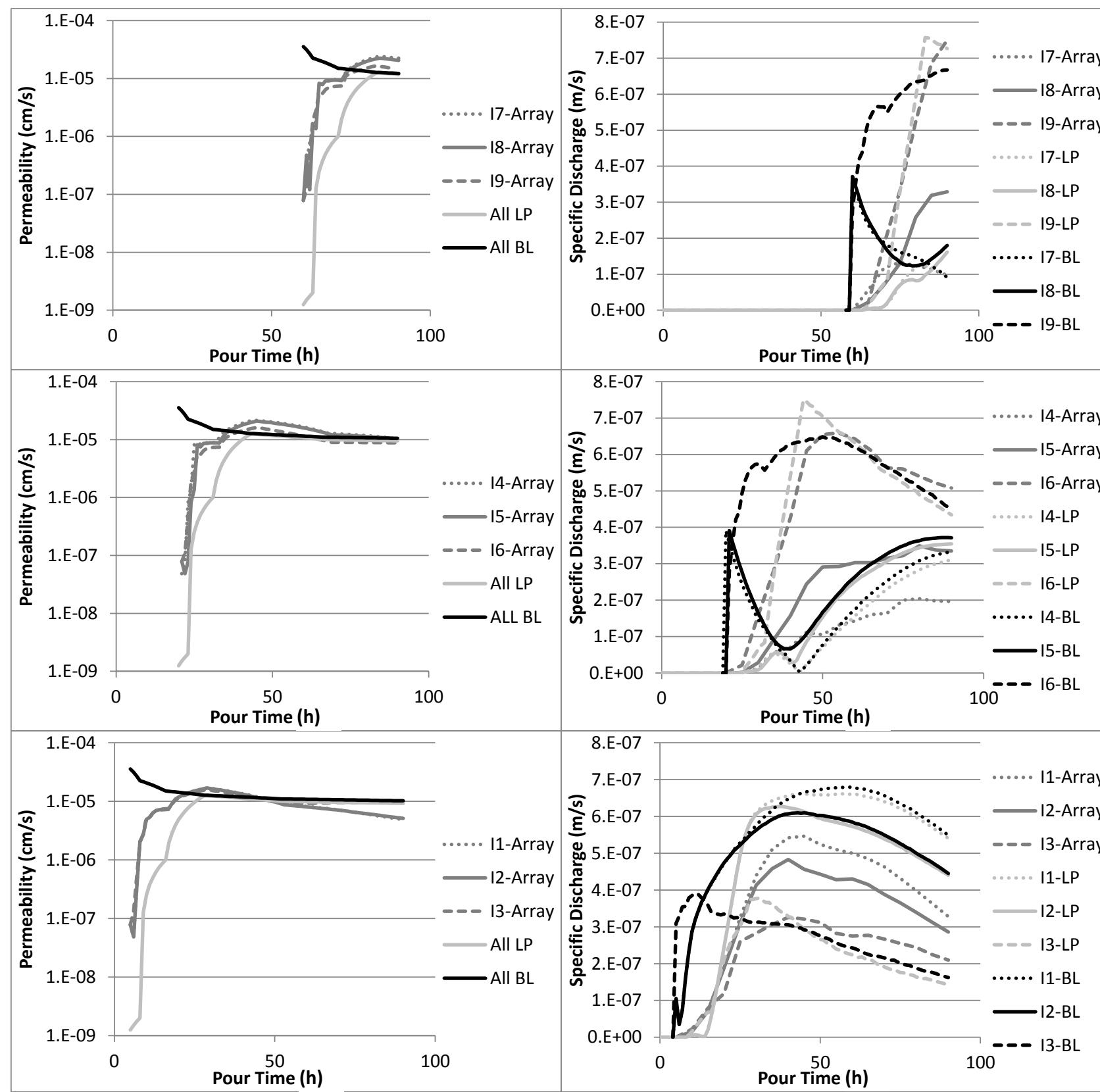

Permeability



Specific discharge

\section{Figure 8 Plots of showing permeability and specific discharge with pouring time at the nine monitored zones}

The permeability graphs only show five lines as all the BL and all the LP model curves are equal. The first observation is that the AR permeability curves are more similar to the LP curve than the BL curve. Both the LP and AR curves follow the same sort of trends. All of the curves start to coalesce around 28-30 hours of curing.

This suggests two things. The similarity between the early curing age LP and AR curves suggest that the use of the stress-time method may be valid way of modelling how the early curing age paste is behaving. As the AR curve also follows the other curves at later curing ages it suggest that the stress-time method is able of capturing the behaviour in the later parts of the curing cycle.

The specific discharge curves show that both the AR and LP curves have similar behaviour throughout the entire pour, whereas the BL model has very different behaviour for the first 20-24 hours but then starts to 
follow the other curves. Again this suggests that the stress-time method is able to capture both the early and later stages of curing.

\subsubsection{Determining water discharge from CPB into rock mass}

The final comparison between the models is to determine the amount of water that is calculated to leave the model. By determining the specific discharge for all of the zones immediately adjacent to the rock wall the discharge from the bottom of the stope and the side of the stope was determined. These are shown in dashed and dotted lines on Figure 9. Solid lines show the total discharge for each model.

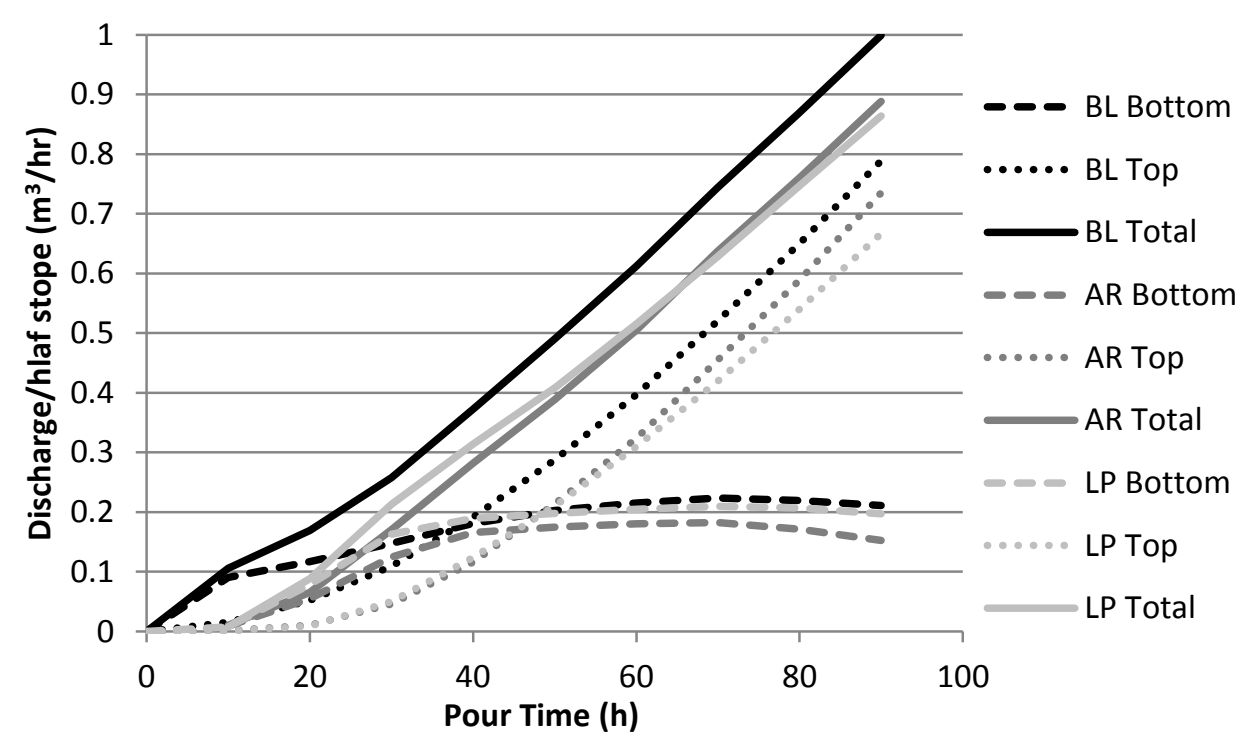

\section{Figure 9 Discharge from stope in $\mathrm{m}^{3} / \mathrm{h}$}

A quick analysis of this chart shows that these flows are a high given what has been observed in the field and laboratory. The AR and LP curves are very similar and would produce a total discharge volume of around $35 \mathrm{~m}^{3}$. As the entire half stope volume is $108 \mathrm{~m}^{3}$ the drainage would account for approximately a third of the total volume. This drainage volume is too high and is likely due to the PWP = 0 boundary condition at the rock-paste interface. However, this represents an initial attempt at using this model to determine water outflow and future work is planned in this area.

\section{Conclusions}

The purpose of this paper was to examine the behaviour of CPB in the upper layers of the CPB column where field instrumentation shows that isotropic behaviour takes place. To this end an examination of the compression behaviour of CPB was conducted using laboratory consolidation data and field instrumentation. This examination of the laboratory data demonstrated that, for three different pastes, by the time the paste material skeleton starts to take load it is generally strong and stiff enough to resist the weight of the material above it. This said all three pastes did experience a small amount of compression prior to this point.

Three models were run to examine the impact of stiffness and permeability. The first two, the BL and LP models, inputted a direct permeability and coefficient of volume compressibility $\left(m_{v}\right)$. The BL model was determined from laboratory testing and the LP model was determined through model calibration. The third, the AR model, determined the coefficients of volume compressibility and consolidation as a function of curing time and stress. The idea was to see how this function's outputs would compare to the other models.

In general it was found that the LP and AR model produced similar results. It is important that the AR model was able to replicate the behaviour of the LP model in both the early and later stages of curing. 


\subsection{Further work}

The following items are areas of future work:

- Examine better methods of determining the early age consolidation parameters.

- Examine the validity of the PWP $=0$ boundary condition.

- Use stress-time approach on actual stope model geometries and input parameters for comparison with the results from in situ instrumentation.

- Explore the relationship between consolidation and specific discharge to try and determine the amount of water the CPB mass would release into the rock mass.

\section{Acknowledgement}

Thanks to the Natural Sciences and Engineering Research Council Canada, Barrick Gold Corporation, Inmet Mining Corporation (First Quantum), and Xstrata (Glencore Xstrata) for their support of the $U$ of $T$ Geomechanical Design of Cemented Paste Backfill Systems Project.

\section{References}

El Mkadmi, N, Aubertin, M \& Li, L 2011, 'Numerical analysis of the early response of paste backfill in a vertical stope', Proceedings of the Mines Without borders, CIM Conference \& Exhibition, Canadian Institute of Mining, Metallurgy and Petroleum, Westmount.

Grabinsky, MW, Simon, D, Thompson, BT, Bawden, WF \& Veenstra, RL 2014, 'Interpretation of as-placed cemented paste backfill Properties from Three Mines', in Y Potvin \& AG Grice (eds), Proceedings of the 11th International Symposium on Mining with Backfill, Australian Centre for Geomechanics, Perth, pp. 351-64.

Helinski, M, Fourie, AB, Fahey, M \& Ismail, M 2007, 'Assessment of the self-desiccation process in cemented mine backfills' Canadian Geotechnical Journal, vol. 44, pp. 1148-56.

Helinski, M, Fahey, M \& Fourie, AB 2011, 'A framework for designing and managing cemented mine backfill', in HJ Ilgner, Proceedings of the 10th International Symposium on Mining with Backfill, The Southern African Institute of Mining and Metallurgy, Johannesburg, pp. 261-74.

Itasca Consulting Group, Inc. 2012, FLAC3D: Fast Analysis of Continua in 3 Dimensions, Version 5.0, Itasca Consulting Group, Inc., Minneapolis, http://www.itascacg.com/software/flac3d

$\mathrm{Li}$, L \& Aubertin, M 2010, 'An analytical solution for a nonlinear distribution of effective and total stresses in vertical backfilled stopes', Geomechanics and Geoengineering, vol. 5, no. 4, pp. 237-45.

Simms, P \& Grabinsky, M 2009, 'Direct measurement of matric suction in triaxial tests on early-age cemented paste backfill' Canadian Geotechnical Journal, vol. 46, no. 1, pp. 93-101.

Thompson, BD, Grabinsky, MW, Veenstra, RL \& Bawden, WF 2011, 'In situ pressures in cemented paste backfill - a review of fieldwork from three mines', in RJ Jewell \& AB Fourie (eds), Proceedings of the 14th International Seminar on Paste and Thickened Tailings, Australian Centre for Geomechanics, Perth, pp. 491-504.

Veenstra, RL, Grabinsky, ML \& Bawden, WF 2012, 'A procedure for determining the stresses within a backfilled underground stope', Proceedings of the 65th Canadian Geotechnical Conference, Winnipeg, Canada.

Veenstra, RL 2013, 'A design procedure for determining the in situ stresses of early age cemented paste backfill', PhD thesis, University of Toronto, Toronto.

Veenstra, RL, Grabinsky, ML \& Bawden, WF 2013, 'An examination of the failure mechanisms in modelled cemented paste backfill', Proceedings of the 23rd World Mining Congress 2013, Montreal, Canada.

Veenstra, RL, Grabinsky, Bawden, WF \& Thompson, BD 2014, 'The use of numerical modelling to determine the stress within early age cemented paste used to backfill an underground stope,' in Y Potvin \& AG Grice (eds), Proceedings of the 11th International Symposium on Mining with Backfill, Australian Centre for Geomechanics, Perth, pp. 97-112. 
